\title{
Compendium of the Self-Regulated Education Method in Terms of Various Variables in Flute Education
}

\author{
Emre Ustun \\ Nevşehir Hacı Bektaş Veli University, Faculty of Fine Arts, Department of Music and Performing Arts, Turkey. \\ Email:emreustun1@hotmail.com
}

\begin{abstract}
The emotional, mental, kinesthetic development in the musical instrument training all along the educational process of the individual is great importance. In this context, self-regulated training, which is one of the training methods to be used by the flute instructors, stands out in the development process of the students. The motivation, attitudes, emotional, self-efficacious development of the students towards their instruments supported byselfregulated training can increase the instrument performance. In this study, experimental method was used with the help of self-regulated training method, emotional expression scale, general self-efficacy scales. The study was performed with 22 students who studied flute at the music department. As a result of the study, it was determined that the application of self-regulated training method in flute education had a positive effect on negative expression, self-efficacy. Furthermore, it has been determined that self-regulated training method improves students' ambition, attitudes and motivations in a more conscious, efficient working process towards lessons and instruments.
\end{abstract}

Keywords: Instrument training, Flute education, Self-regulated training, Emotional expression, Negative expression, Self-efficacy.

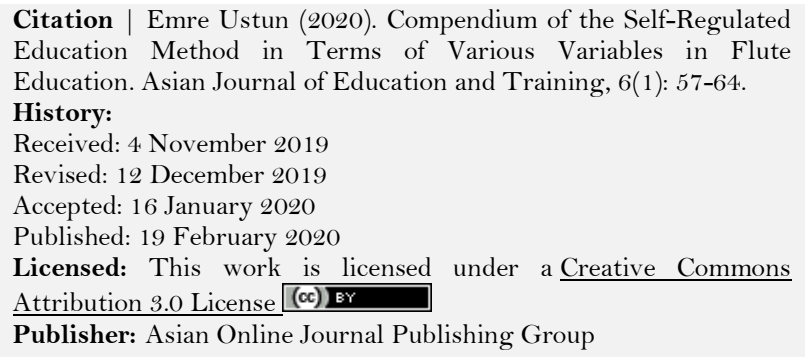

Citation | Emre Ustun (2020). Compendium of the Self-Regulated Education Method in Terms of Various Variables in Flute Education. Asian Journal of Education and Training, 6(1): 57-64. History:

Received: 4. November 2019

Revised: 12 December 2019

Accepted: 16 January 2020

Published: 19 February 2020

Licensed: This work is licensed under a Creative Commons

Attribution 3.0 License (c)) E

Publisher: Asian Online Journal Publishing Group

\section{Contents}

1. Introduction

Funding: This study received no specific financial support

Competing Interests: The author declares that there are no conflicts of interests regarding the publication of this paper.

Transparency: The author confirms that the manuscript is an honest, accurate, and transparent account of the study was reported; that no vital features of the study have been omitted; and that any discrepancies from the study as planned have been explained.

Ethical: This study follows all ethical practices during writing.

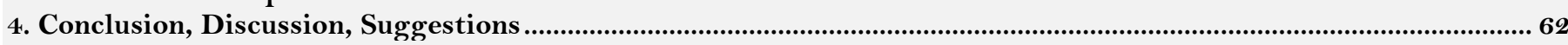

References.. 


\section{Contribution of this paper to the literature}

This study contributes to the existing literature by motivation, attitudes, emotional; selfefficacious development of the students towards their instruments supported by self-regulated training can increase the instrument performance. Additional experimental method was used with the help of self-regulated training method, emotional expression scale, general self-efficacy scales.

\section{Introduction}

Music, as an important form of art, which associates emotions and thoughts, comes into prominence with educational components as a whole in the process of learning and development. At the present time, the fact that music education contributes to personality development and socializing of individuals is increasingly accepted. Beginning from pre-school to higher education institutions, music education intends to develop the musical abilities of individuals who take this education. One of the most influential fields in revealing these abilities is instrument training. "Musical instrument training is one of the sub-dimensions of music education and is divided into various dimensions itself" (Uçan, 2001). Amidst the training of a musical instrument befitting for the individual, he / she will be able to comprehend the technical characteristics of the instrument and to perform it effectively by combining his / her mental and motor skills. In order for a successful instrument training to be carried out, the most effective use of instrument practicing time, effective practicing and learning tactics in instrument training, the development of student success and all stages of the practicing process, and the realization of the student in his / her supervision should be handled by the instrument trainers. Musical instrument practice is considered to be the most basic action in the development of instrument skills (Wagner, 1975; Rosenthal, 1984; Wolfe, 1984; Barry, 1992). Weidenbach (1996) underlines that the practice does not consist of daily routine and that personal tactics and conscious pieces of training should be carried out as well. In order to meet these expectations, the selfregulated training method in flute education aiming the development of musical instrument training and to provide musical skills, can be seen as an effective teaching method in the process of transferring the cognitive and kinesthetic behaviors of the students and help them see music as a whole. Ozmentes (2008) mentioned the importance of this effective teaching method process as follows; playing an instrument is one of the most basic actions in terms of development of instrument skills. The tactics and conscious practice habits used by the student are important factors affecting his / her performance. At this phase, the use of self-regulated training in the process of musical instrument training is an issue that should be accentuated in order to be independent and effective learners. The concept of self-regulated learning can be defined as the competence of students to participate effectively in the learning process in terms of cognitive, motivational and behavioral aspects. People with this skill can plan, organize, observe and evaluate each stage of metacognitive learning processes; from a motivational point of view, they see themselves as adequate and effective, and create the most convenient environment for behavioral learning. The self-regulated training method was defined as the degree of active participation of individuals in their own learning processes in terms of metacognition, motivation and behavior according to Zimmerman (1989). In their study named "Self-regulated Learning: Models and Applications", Sarı and Akınoğlu (2009) stated Zimmerman's self-regulated training method and its importance as follows: Self-regulation is a multi-component, iterative, self-managed processes that target cognition, emotions, actions and characteristics of the environment for one's own purposes (Cascallar et al., 2006). He emphasized that self-regulated learning should not only be limited to cognitive or metacognitive strategies but also motivational strategies should be used to provide learning as well (Boekaerts, 1993). Self-regulated training in terms of students; is the person who is motivated to carry out a task with success, to set realistic goals in order to fulfill the task and to use effective strategies, to be a self-follower to measure effectiveness, to adjust or organize the use of strategy when necessary (Zimmerman, 1989). Therefore, Zimmerman defines self-regulated learning as thoughts, emotions, and behaviors that are created by the learner to reach a goal. Learning is seen as an anticipatory activity for the learners, rather than as an implicit event which is a response to teaching. Consequently, self-regulation is not a mental skill or an academic performance skill, but a self-directing process that enables learners to transform their mental abilities into academic performance skills (Zimmerman, 2002). In this context, Zimmerman's Social-Cognitive Self-Regulated Learning Model which is one of the models studied in self-regulated learning, is listed under the following headings:

1. Forethought phase: Indicates the processes and beliefs before the effort to learn. This phase consists of two types of processes:

a. Task analysis: Includes goal setting and strategy planning.

b. Self-motivation: Covers the students' ability to direct their inner interests and learning goals towards learning.

2. Performance phase: Indicates the processes during behavioral implementation. This phase consists of two types of processes:

a. Self-control: Processing of selected methods or strategies in the pre-thinking phase. Thus, students can concentrate on the goal and make the best use of their efforts. This can be achieved with imagery, selfinstruction, and attention focusing and task strategies.

b. Self-observation: Involves the person to keep a record of the events related to him / herself and to try to find out the reasons for these events.

3. Self-reflection phase: refers to the processes taking place after each learning effort. This phase consists of two types of processes:

a. Self-judgment: The student's judgment after a learning effort. The student can perform his / her own selfevaluation by comparing his performance with the performance of another person or with any standard.

b. Self-reaction: After a learning effort, the boost in self-satisfaction increases the motivation for subsequent learning efforts.

The adaptive processes and belief of success of individuals are important in the implementation stage of these phases of Zimmerman. In this sense, emotional expression is of great importance for the adaptive process of individual functions. In this context, giving credit to basic emotions may be useful in this training process taking 
the musical instrument training into consideration. According to Plotnik (2009) the concept of emotion consists of four components. Interpretation or evaluation of a stimulus according to the individual's situation, to experience fear and happiness, to have physiological changes, laughing and crying. When these four components come together, emotional expression can be defined as the outpouring of internal processes with various observable responses. Further, when the individual differences in musical instrument training are considered, emotional expressions and methods may vary in each individual. From this point of view, the positive direction of the individuals who have the instrument training can be improved in the sense that they can be successful in the education process. The concept of self- efficacy comes to the fore in terms of the development process of this belief. Kotaman (2008) defined the concept of self- efficacy as the formation of a personal belief that the individual can achieve a certain task. According to Kotaman, self-efficacy belief is a concept that influences students' motivation. Self-efficacy plays a critical role in the acquisition of a new skill or in the realization of a new learning and then in the implementation of this new skill or learning. According to Bandura (1989); The self-efficacy belief determines the level of motivation of a person. This level of motivation determines how much effort will be made for the given task and how much continuity will be made in this effort. In this respect, the strength of the individual's ability to keep strong increases continuity and effort (Schunk, 1981; Zimmerman and Ringle, 1981; Bouchard, 1990). Based on these explanations, the use of self-regulated education in instrument training is paramount in terms of the emotional, mental and kinesthetic development processes of the students. By the implementation of this training process, students will be able to analyze the problems they will encounter all along the musical instrument training process more easily, besides their learning performance and instrument performance will be improved. The objectives targeted for musical instrument training will be accomplished with the systematic and scheduled planning and implementation of the self-regulated process. The fact that the students perform their practice in patience and in a systematic way will enable them to reach to a better level day by day and to reach the intended steps easily throughout the flute education process. In addition to all these, the students' musical perception ability, musical life, their emotional expression towards the lesson and the instrument, motivation, attitude, and selfefficacy will develop. Hence, a more healthy education process will take place and an important step will be taken in raising successful individuals.

\subsection{Problem Statement}

In the context of all this, the problem statement of this study is formed as: "What is the effect of self-regulated training on students' emotional, mental and kinesthetic development in flute education?"

\subsection{Sub-Problems}

What is the effect of using self-regulated training on flute students in terms of emotional expression in flute education?

What is the effect of self-regulated training on flute students in terms of self-efficacy in flute education?

What are the opinions of flute students on the tactics of flute in the process of self-regulation in flute education?

\subsection{Aim of the Research}

In music departments, effective music education of the students will enable them to develop personal and social aspects and consequently gain the elements of success, trust, and respect. From this perspective, an effective flute training should be implemented with a program arranged in accordance with the objectives and goals. In this application, it is believed that self-regulated training will positively affect the personal development of students for an effective flute training. The aim of this research by implementing the self-regulating training is; to reveal the effects of emotional, mental and kinesthetic development of these flute students who study in music departments.

\subsection{Limitations}

This research is limited to 5 items below:

1. Nevşehir Hacı Bektaş Veli University Faculty of Fine Arts Department of Music and Performing Arts 20182019 academic year students taking flute education.

2. Scales used to determine self-regulated education and emotional expression and self-efficacy.

3. Students' views on the self-regulated education process.

4. Observations on the study.

5. Resources available as a result of a literature review.

\section{Methodology}

The research is a descriptive study in terms of the method followed and the nature of the data collected. "Descriptive analysis: according to this approach, the data obtained are summarized and interpreted according to the previously determined themes. The purpose of this type of analysis is to present the findings to the reader in an edited and interpreted manner (Ylldırım and Şimşek, 2006)." Karasar (2009) states the content of research methods and techniques as the techniques that embody the entire mental efforts of the problem from the definition to the result. In this section; the scientific method of the research, the model of the research, the universe and the sample, the data collection tools, the validity and reliability studies, and the analysis of the data are given. Yıldırım and Şimşek (2005) explained that in order to learn different aspects and formations of reality, the researcher should reveal different points of view, different meanings, different indicators and sources about the phenomenon that he is investigating. According to Karasar (2009) reaching a general judgment about the universe requires arranging with a scanning done on the entire universe or a group, an example, a sample taken from it. The research is a descriptive one which is arranged in the scanning model to determine the development of students' emotional expression and self-efficacy processes and their opinions in this process. 


\subsection{Universe and Sample}

The universe of the study consisted of students who received individual flute training in the music departments of the faculties of fine arts, and the sample was composed of students from the Department of Music and Performing Arts of the Faculty of Fine Arts of Nevşehir Hacı Bektaş Veli University.

\subsection{Research Group}

The research group was formed by 22 students who received individual flute training during 2018-2019 academic year. In this formation, students' grade, success level, level, technical level and personal development were taken into consideration in order to form the experimental and control groups heterogeneous. Students' grade point average, regular class participation, mastery on their instruments in terms of technique and tone, being in an adequate level on the basis of etude and piece, and being graduated from fine arts high school were examined in the formation of groups. Students' grade, level of success, degree, technical level and personal development were examined to form groups. 1st, 2nd, 3rd, and 4th-grade students were grouped equally and 11 of all assigned to the experimental group while the other 11 to the control group.

\subsection{Experimental Research Design}

In the study, experimental and control groups were formed in order to start the experimental process after literature review. After a heterogeneous formation ensured, the etudes which they were expected to continue in accordance with their levels, were determined during the 10-week education period. In this context, the etude book and the level of the students in the previous year were taken into consideration. Each student is expected to complete one etude per week in a 10-week period. In this respect, Taffanel Gaubert, Köhler Etüt and Romantic Köhler flute etude books were used. Before the experimental study, emotional expression and self-efficacy scale which has validity and reliability was applied to both groups as a pre-test. After the pre-test, the 10-week training process was initiated, in this process, the researcher continued the in-class and out-class work with the experimental group using self-regulated training. This process is based on Zimmerman's model of social cognitive self-regulated learning. Task analysis, Self-motivation, Self-control, Self-observation, Self-judgment, and Selfreaction stages were continued during 10 weeks with audio and video recordings in addition. In accordance with self-regulated education, no intervention was made to the control group. During the out-class studies, the etudes given to both groups were monitored by the researcher. At the end of the 10-week training period, the emotional expression and self-efficacy scale were re-administered to the students. The obtained data were analyzed by comparing with the first and last form. In addition, each week, the students in the experimental group were asked to evaluate themselves under the main topics related to their work processes. At the end of 10 weeks, the data obtained were analyzed and common opinions of students about self-regulated training strategies were determined and interpreted.

\subsection{Data Collection Tool}

Under this title, self-regulated training model was used to test the research experimental groups. In this context with the implementation of this training the techniques used in the analysis of the data obtained from the emotional expression and self-efficacy scale, the views of the students, the planning of the research and the process are included. The experimental method was used in the study. The "pretest-posttest design" of this method was preferred. In this respect, the study was carried out with the students of Nevşehir Hacı Bektaş Veli University Fine Arts Faculty Music and Performing Arts Department who had been taking flute education. In the study conducted with 22 students, while 11 of them constituted the experimental group, the other 11 were the members of the control group.

\subsection{Berkeley Emotional Expression Scale and General Self-Efficacy Scale}

The aim of this study was to determine the emotional expression characteristics of the students selected by self-regulation training for the experimental stage. By adhering to this goal, the Berkeley Emotional Expression scale developed by Gross and John (1995) was used by Akın (2011). The sub-dimensions and items of the scale are summarized by Celik (2013) as follows: The Berkeley Emotional Expression Scale consists of three sub-dimensions: positive expression, negative expression, and impulse intensity. In the scale consisted of 16 items in total; items $1,4,6$ and 10 are related to positive expression; items 3,5,8,9 and 13 are related to negative expression; items $2,7,11,12,14,15$ are related to impulse intensity. Furthermore, the scale gives a total emotional expression score. Participants indicate the degree to which they agree with each of the items on a 7-point Likert-type scale. The range of the scale is 16-112 (Akm, 2011). Besides, it was aimed to determine the self-efficacy characteristics of the students selected for the experimental phase through self-regulated training. The concept of self-efficacy has been defined by Yokus and Yürüdür (2015) as individuals to seek for possible solutions to the problems they face, constantly controlling the thinking and evaluating the processes, having the self-confidence to solve their problems, and believing that they will cope with these problems. The formation and development phase of the scale is summarized by Ustun (2016) as follows; the self-efficacy scale was first presented by Jerusalem and Schwarzer (1979) and consist of 20 items. After 2 years, it was limited to 10 items by the researchers. The scale was translated into Turkish by Yeşilay (1993); Schwarzer (2004). The scale is a four likert scale and the range of it is between 20 and 80. This scale was obtained from the Phd study named "A State Flow Model: The Relationships Among Stres Control, General Self-Efficacy, State Anxıety, Life Satısfactıon and State Flow” by Sahranç (2008) and reliability and validity studies were regarded as suitable for this study. In addition, in order to ensure the reliability of the scales for this research, a pilot scheme was conducted on 70 students with yhe exception of the experimental group and the control group. As a result of the data obtained and analyzes, three sub-dimensions of the emotional expression scale and one-dimensional structure of the self-efficacy scale were confirmed. The internal consistency of the scales (Cronbach's alpha) were calculated as $\alpha=.88$ for the emotional expression scale and $\alpha=.80$ for the general self-efficacy scale. These results indicate that the measurements are reliable. 


\subsection{Data Analysis}

Quantitative data analysis methods were used to evaluate the content analysis of the data obtained. The steps followed in the analysis and interpretation of the quantitative data obtained from the research and the formatting of the findings as a result of these stages are given in the order of sub-problem. SPSS program was used to analyze the data. Pre-test and post-test scores of the experimental and control groups were determined by using t test. The level of significance was accepted as $\mathrm{p}<, 05$ in the interpretation of the results.

\section{Results and Interpretations \\ 3.1. Results of First Sub-Problem}

Table-1. Independent t-test results of emotional expression levels of students in the study group according to the situations of self-regulated training.

\begin{tabular}{|c|c|c|c|c|c|c|}
\hline Emotional Expression & & $\mathbf{N}$ & $\mathbf{X}$ & $\mathbf{t}$ & $\mathbf{P}$ & S.S \\
\hline \multicolumn{7}{|c|}{ Positive Expression (First sub-dimension) } \\
\hline \multirow[t]{2}{*}{ Experiment } & Pre-test & 11 & 5,5909 & & & \\
\hline & Post-test & 11 & 5,909 &,- 672 &, 517 & 1,56960 \\
\hline \multirow[t]{2}{*}{ Control } & Pre-test & 11 & 4,9318 & & & \\
\hline & Post-test & 11 & 5,4318 &,- 991 &, 345 & 1,67332 \\
\hline \multicolumn{7}{|c|}{ Negative Expression (Second sub-dimension) } \\
\hline \multirow[t]{2}{*}{ Experiment } & Pre-test & 11 & 5,5909 & & & \\
\hline & Post-test & 11 & 4,7727 & 1,867 & ,092 & 1,45384 \\
\hline \multirow[t]{2}{*}{ Control } & Pre-test & 11 & 4,4848 & & & \\
\hline & Post-test & 11 & 4,3636 & ,329 & ,749 & 1,22268 \\
\hline \multicolumn{7}{|c|}{ Impulse Intensity (Third sub-dimension) } \\
\hline \multirow[t]{2}{*}{ Experiment } & Pre-test & 11 & 5,5606 & & & \\
\hline & Post-test & 11 & 5,5455 & 1,007 & ,976 & 1,60114 \\
\hline \multirow[t]{2}{*}{ Control } & Pre-test & 11 & 5,4242 & & & \\
\hline & Post-test & 11 & 5,1901 & ,132 & ,338 &, 77119 \\
\hline
\end{tabular}

Note: $\mathrm{p}>.05$.

As seen in Table 1 the pre-test and post-test total scores of the students in the emotional expression scale of the study group did not reveal a significant difference in the three sub-dimensions in terms of the application of self-regulated training. Depending on this situation when the average scores of the groups are compared, for both the experimental and the control groups, there was a decrease in the first sub-dimension, and an increase in the second sub-dimension and the third sub-dimension. Notwithstanding the average score difference was close to the experimental-control group in terms of the first and third sub-dimensions of these increases and decreases, the decrease in negative expression which is the second sub-dimension was remarkably evident. The pretest-posttest average score difference of the control group was ",12" and the pretest-posttest average score of the experimental group was ",82". In consonance with these findings, it can be said that the utilization of the self-regulated training model has a significant effect in terms of negative expression while not having a significant effect on positive expression and impulse intensity.

\subsection{Results of Second Sub-Problem}

Table-2. Independent t-test results of self-efficacy levels of students in the study group according to the situations of self-regulated training.

\begin{tabular}{l|c|c|c|c|c|c}
\hline \multicolumn{1}{c|}{} & $\mathbf{N}$ & $\mathbf{X}$ & $\mathbf{t}$ & $\mathbf{P}$ & S.S \\
\hline Experiment & Pre-test & 11 & 2,6818 & & & \\
\hline & Post-test & 11 & 3,1818 & $-3,690$ &, 004 &, 44944 \\
\hline Control & Pre-test & 11 & 2,9091 & & & \\
\hline & Post-test & 11 & 2,7455 & 1,390 &, 195 &, 39057 \\
\hline Note: $\mathrm{p}>.05$.
\end{tabular}

As seen in Table 2, the pre-test and post-test total scores of the students in the study group from the selfefficacy scale showed a significant difference in the experimental group in terms of the utilization of self-regulation training $(\mathrm{P}:, 004<.05)$. When the control group data were examined, it was seen that there was no significant difference. When the average values of the groups were examined, a significant increase was observed in the experimental group between the pre-test and post-test data, whereas in the control group there was a decrease in the same situation. (Experiment X: 2,6818-3,1818 - Control X: 2,9091-2,7455). According to these findings, it can be said that the students have a significant effect on their self-efficacy with the utilization of self-regulated education.

\subsection{Results of Third Sub-Problem}

In the self-regulated training process regarding the third sub-problem, the opinions of the flute students on the tactics of practicing were requested in writing for each week. In this context, the common opinions of the students were determined. In terms of the study process, task analysis and self-motivation for the forethought phase, selfcontrol and self-observation for the performance phase, self-judgment and self-reaction for the self-reflection phase were selected. In this sense, students' opinions and interpretations for self-regulated tactical practice have been formed as follows;

Task analysis: It was seen that students set goals in terms of time concept in their etudes. In this sense, it is verified that they use the working strategy in the determined sections of their etudes in certain time periods of the 
week. In addition, after the deciphering stage, they stated that they studied by determining their tempo and increasing the metronome speed of their etudes every week.

Self-motivation: The students interpreted this phase that they enjoyed the tone of their instruments and the time they had with them, they worked with more pleasure if the etudes are appropriate with their level, their instructors have a great influence on them to enjoy the lessons and instruments. They also pointed out that they postponed practicing for a period of time without forcing themselves if they are tired of studying.

Self-control: In general, the students stated that they conducted a harmonic study in the first phase of the etudes. After this stage, their strategies are listed as follows; making the rhythmical articulation (Bona method) of the piece, after having a general idea for the piece tracking the notes by a slow-paced finger study without blowing the instrument, studying the arpeggio series and gamut in the tonality related to their etudes, studying the sections that they have determined for each day, working in the same place repeatedly by marking the places where they are failed, reaching the intended tempo by increasing the speed of the metronome step by step, placing the staccato, legato, trill and nuances into the piece. They stated that they enforced their concentration with these targeted strategies, they increased their motivation because they felt more conscious about their effort, the wish that the performance of the instrument would be better in their minds, they enjoyed the work and felt trouble in the days when they could not work.

Self-observation: At this stage, the students stated that they observed themselves in the final stage of the etude by taking video recordings. They also stated that they had been listening their etudes from different performers during the study process and that it was a great contribution of the flute educator to play the piece or etude as an example in the course.

Self-judgment: At this stage, the students stated that they were judging themselves by analyzing their video records for each week. In this process, that stated that after taking notes about their technique, tone, tempo, articulation, handing, and tonguing coordination, holding and body posture, in the subsequent works, they tried to organize these deficiencies together with the lecturer and at this stage they stated that they made progress in the performance sense by comparing the records they found on the internet with their own performances.

Self-reaction: At this stage, students stated that they realized their learning efforts and desires advanced, that they study on the instrument more consciously and with the help of this consciousness they had a positive effect on their motivation and performances, their practicing time was more fluent and that they wanted to reach more advanced techniques and levels by working without being bored.

\section{Conclusion, Discussion, Suggestions}

\subsection{Conclusion}

The research was conducted to determine the development of emotional expression and self-efficacy tendencies with the utilization of self-regulated training in the in-class and extracurricular studies of the students who received individual flute training. In this study, experimental and control student groups were formed and experimental studies were conducted with 22 students. During this study, each of the 11 students composing the experimental group had been trained in accordance with the level. Both in and outside the course, these studies were used in accordance with the objectives and goals. This process was carried out together with the researcher in the course work, and was supervised by the researcher in the extracurricular studies. During the same period, there has been no intervention in the in-class and extracurricular studies of the control group students in terms of selfregulated training. The etudes were done for both groups in accordance with their level. Taffanel Gaubert, Köhler and Romantic Köhler flute education books were used for these etudes. During this 10-week period, the applications of each student in the experimental group were carefully monitored. The emotional expression and self-efficacy scales which were reliability ensured were applied as a pre-test by a pilot study. At the end of the 10th week, the same scales were applied to the students as the final test and the implementation stage of the study was completed. In this respect, the results have been reached by comparatively analyzing the data within the experimental and control groups. In this context, there was no significant difference between the pre-test and posttest total scores of the students in the experimental group on the emotional expression scale and the scale applied as a result of self-regulated education. When the average score values of the scale consisting of three subscales are compared, it is seen that there are increases and decreases in accordance with the dimensions. In terms of the subdimensions of positive expression and impulse intensity of these increases and decreases, the average score gap of the experimental and control groups is close. In the second sub-dimension which is the negative expression, the decrease was evident. This situation shows that students who have received self-regulated training in flute education have positive development in their tendencies that are negative in terms of emotional expression. A significant difference was found in the pre-test and post-test total scores obtained from the scale applied to measure self-efficacy development with self-regulated education. In addition, pre-test average scores of the experimental group students were significantly increased after the 10-week period compared to the answers they gave as final tests. When the mean scores of the control group were examined, an opposite situation was observed and the mean scores decreased. This situation shows that the students who take flute education with self-regulated training have a positive development in terms of self-efficacy. The pre-test post-test data of the two scales, the data obtained by comparing the experimental and control groups showed that the active use of studying with self-regulated training in individual flute education during the in-class and extracurricular studies had a positive effect on negative expression and self-efficacy. Besides, in the process of self-regulated training, the opinions of the flute students in terms of their practicing tactics were interpreted. In this context, the consociate opinions of the students were identified. Task analysis in terms of work process, self-motivation, self-control, self-observation, self-judgment, self-reaction main titles have been selected. When the comments given by the students in general terms are examined, it has been determined that self-regulated tactical studies have positive effects. They interpreted about the efficient use of time, starting from the basic steps, keeping the study time disciplined, leaving the techniques and ornaments to the last phase, self-criticizing by taking video recordings, comparing their performance with other performances, increasing their affection to the instrument and the desire to study, and the great importance 
of the effect of instrument educator. In this sense, we can say that self-regulated strategies positively affect students' willingness to work, attitudes and motivations, and musical consciousness positively.

\subsection{Discussion}

Topaloğlu (2011) aims to determine the self-regulated learning strategies used by string instrument students at different levels in his research named 'Updating Self-Regulated Learning Strategies Used by Stringed Instrument Students at Different Levels'. In order to determine self-regulated learning strategies, 6 string instrument students were asked to express the problems they encountered in their works. Unstructured interviews were conducted in order to identify the strategies students used in their process of instrument practicing. In this context, self-regulated learning strategies used by the students were determined. At the end of the study, it was observed that all students did self-observation, self-evaluation, self-teaching, long and short term goals determination, and strategic planning. Ozmentes (2008) stated in his study named 'Slf-Regulation Learning Tactics in Instrument Education' that the use of self-regulated learning tactics should be emphasized in the instrument study process in order to be independent and effective learners. When the self-regulated learning tactics of the students in the research were examined, it was seen that the affective features in the pre-performance phase intertwined with metacognitive and cognitive tactics. Especially in the pre-performance phase, it was determined that students had a very rich tactical approach in terms of tactical planning. Hallam (2001) stated that there is a need for metacognitive tactics such as the effective instrument practicing process, the awareness of the difficulties of the work in the study process, the choice of tactics to be used in this stage, observing the studying process, developing alternative tactics and evaluating them within the framework of these processes. Zimmerman (1998) in the first phase of the circular self-regulated learning model, revealed that students had a self-efficacy process in addition to the basic activities such as targeting and analyzing the structural features of the work. The students' cognitive and metacognitive skills are accompanied by many characteristics such as attitude, interest and selfefficacy. In their study named 'A Theoretical Overview of Self-Regulated Learning”, Yıldızlı and Saban (2015) revealed that self-regulation skills have a strong relationship with motivational factors such as self-efficacy, attitude, interest, and value, and that self-regulated learning environments need to be developed. He also stated that there were not enough number of experimental studies covering the teaching environments where selfregulated learning was applied. Hardalac (2012) in her study named 'The Effect of Self-regulated Learning Method on Individual Study Process of Dimension of Instrument Training' has revealed the level of effectiveness of the use of self-regulated learning method by Gazi University Primary School Teaching Department students to individual study processes. Subsequently, it was determined that experimental group students using self-regulated learning method in the individual instrument study process made this process more effective and efficient than the control group, by interviews and video observations. In their study named 'The Impact of Goal Orientation on Self-regulation and Performance among College Students", Bouffard et al. (1995) examined how students' selfregulation and academic performance differ in learning. The results showed that there was a systematic relationship between self-regulation and academic achievement. Nielsen (2010) has identified in his study named 'Self-regulating Learning Strategies in Instrumental Music Practice' how two advanced conservatory students use their own learning strategies. The findings have shown that students have comprehensive self-regulating skills that enable them to optimize their learning and performance by taking into account interpersonal, contextual and internal conditions. To the degree that the results obtained from these studies, it is understood that self-regulation education practice is important for students in terms of the development of both their success and personal characteristics. Based on these results, it can be seen that the study had parallels with the above studies. In addition, it was stated that the studies that will demonstrate the availability of self-regulated training within the scope of musical instrument training are insufficient. This indicates the study becomes more of an issue. In addition, in order for students to gain knowledge and experience about the strategies they will use within the scope of self-regulated training in their individual studies, there is a great responsibility for the instrument trainers. The primary objective of the trainers should be to develop their students' motivations and individual behaviors in terms of emotion and competence in their studies by programming their students' strategic work and working time periods in this context.

\subsection{Suggestions}

1. Considering the positive approaches and interests of the students in the study, it can be thought that selfregulated education can help the students to solve their problems by making different studies in terms of providing students with course success and instrument development.

2. In order to better understand the musical education, which is a social, cultural and artistic phenomenon, the trainers should have priority objectives in order to increase the interest of their students in the musical instruments and to enable them to reach the targeted musical behaviors.

3. Self-regulated training should be added as a subject area into instrument education programs.

4. To achieve more precise generalizations, applying the study with a larger sample group over a longer period may make the study more meaningful.

5. Course schedules of individual instrument courses given in universities should be developed, more attention should be paid to teaching methods and more time should be reserved for practice.

6. The trainers who teach music in universities should perceive students as a whole and think about all their personal characteristics, and they should show a consistent, developing and understanding approach.

7. It is suggested that researches about the methods for individual instrument training and the studies related to these methods should be carried out and it is recommended to multiply the resources available to students and trainers.

8. Individual instrument classes should be enriched in content and method.

9. In order to create a musical consciousness and to raise awareness of this consciousness, the studies to be conducted should be given importance in the university students. 
10. In order to create a musical consciousness within the scope of the individual instrument course of the university students, the studies that will have a positive impact on their personal development should be given importance in their in-class and extracurricular studies.

11. It is suggested that individual instrument trainers should be exemplary models for students, and they should constantly improve themselves by keeping their motivation high.

\section{References}

Akın, A., 2011. The validity and reliability of the Turkish version of the Berkeley expressivity scale. Procedia-Social and Behavioral Sciences, 30: 27-33.Available at: https://doi.org/10.1016/j.sbspro.2011.10.006.

Bandura, A., 1989. Human agency in social cognitive theory. American Psychologist, 44(9): 1175-1184.Available at: https://doi.org/10.1037/0003-066x.44.9.1175.

Barry, N.H., 1992. The effects of practice strategies, individual differences in cognitive style, and gender upon technical accuracy and musicality of student instrumental performance. Psychology of Music, 20(2): 112-123.Available at: https://doi.org/10.1177/0305735692202002.

Boekaerts, M., 1993. Being concerned with well-being and with learning. Educational Psychologist, 28(2): 149-167.Available at: https://doi.org/10.1207/s15326985ep2802_4.

Bouchard, B.-T., 1990. Influence of self-efficacy on performance in a cognitive task. The Journal of Social Psychology, 130(3): 353363.Available at: https://doi.org/10.1080/00224545.1990.9924591.

Bouffard, T., J. Boisvert, C. Vezeau and C. Larouche, 1995. The impact of goal orientation on self-regulation and performance among college students. British Journal of Educational Psychology, 65(3): 317-329.Available at: https://doi.org/10.1111/j.20448279.1995.tb01152.x.

Cascallar, E., M. Boekaerts and T. Costigan, 2006. Assessment in the evaluation of self-regulation as a process. Educational Psychology Review, 18(3): 297-306.

Celik, K., 2013. The effect of role ambiguity and role conflict on performance of vice principals: The mediating role of burnout. Eurasian Journal of Educational Research, 51: 195-213.

Gross, J.J. and O.P. John, 1995. Facets of emotional expressivity: Three self-report factors and their correlates. Personality and Individual Differences, 19(4): 555-568.Available at: https://doi.org/10.1016/0191-8869(95)00055-b.

Hallam, S., 2001. The development of metacognition in musicians: Implications for education. British Journal of Music Education, 18(1): 2739.Available at: https://doi.org/10.1017/s0265051701000122.

Hardalac, N., 2012. The effect of self-regulated learning method on the individual education process in instrument education dimension (example of Gazi University classroom teaching department)" Gazi University Educational Sciences Institute Fine Arts Education Department Music Teaching Department, PhD Thesis, Ankara.

Jerusalem, M. and R. Schwarzer, 1979. The general self-efficacy scale.

Karasar, N., 2009. Scientific research method. Ankara: Nobel Publishing.

Kotaman, H., 2008. Literature review on improving self-efficacy belief and learning performance. Journal of Uludağ University Faculty of Education, 21(1): 111-133.

Nielsen, S., 2010. Self-regulating learning strategies in instrumental music practice. Music Education Research, 3(2): 155-167.

Ozmentes, S., 2008. Self-regulated learning tactics in instrument education. Journal of İnönü University Education Faculty, 9(16): 157-175.

Plotnik, R., 2009. Introduction to psychology. Istanbul: Kaknüs Publishing.

Rosenthal, R.K., 1984. The relative effects of guided model, model only, guide only, and practice only treatments on the accuracy of advanced instrumentalists' musical performance. Journal of Research in Music Education, 32(4): 265-273.Available at: https://doi.org/10.2307/3344924.

Sahranç, Ü., 2008. One-state flow model: Stress control, general self-efficacy, state anxiety, life satisfaction and flow relationships. Sakarya University Faculty of Education Journal, 16: 122-144.

Sarı, A. and O. Akınoğlu, 2009. Self-regulated learning: Models and applications. M.Ü. Atatürk Faculty of Education Journal of Educational Sciences, 29(29): 139-154.

Schunk, D.H., 1981. Modeling and attributional effects on children's achievement: A self-efficacy analysis. Journal of Educational Psychology, 73(1): 93-105.Available at: https://doi.org/10.1037/0022-0663.73.1.93.

Schwarzer, R., 2004. Psychology of health behavior: Introduction to health psychology. Hogrefe Verlag.

Topaloğlu, O., 2011. Examining the self-regulatory learning strategies used by string instrument students at different levels. 2nd International Conference on New Trends in Education and Their Implications 27-29 April, Antalya-Turkey.

Uçan, A., 2001. A general overwiev of music teaching in our country. In A. Say (Ed.), Music teaching. Ankara: Music Encyclopedia Publications. pp: 115- 132 .

Ustun, E., 2016. A case study on the state - trait anxiety levels, general self-efficacy, and stress-control skills of undergraduate students having music education. Journal of Human Sciences, 13(2): 3529-3541.

Wagner, M.J., 1975. The effect of a practice report on practice time and musical performance" In C.K. Madsen, C.A. Prickett (Ed.) Applications of Research in Music Behavior. Alabama: Alabama University Press. pp: 125-130.

Weidenbach, V.G., 1996. The influence of self-regulation on instrumental practice.

Wolfe, D.E., 1984. Improve practice with motivational contracts. Music Educators Journal, 71(1): 34-41.Available at: https://doi.org/10.2307/3396331.

Yeşilay, A., 1993. Generalized self-efficacy scale. [Accessed 24 March 2004]

Yıldırım, A. and H. Şimşek, 2005. Qualitative research methods in social sciences. Ankara: Seçkin Publishing.

Yıldırım, A. and H. Şimşek, 2006. Qualitative research methods in the social sciences. Ankara: Seçkin Publishing.

Yıldızlı, H. and A. Saban, 2015. A theoretical view on self-regulated learning. The Journal of International Education Science, 2(4): 97-118.

Yokus, T.M. and F. Yürüdür, 2015. The relationship between metacognitive awareness and self-efficacy levels in pre service music teachers. Turkish Journal of Arts and Social Sciences, 1(1): 22-34.

Zimmerman, B.J., 1989. A social cognitive view of self-regulated academic learning. Journal of Educational Psychology, 81(3): 329339.Available at: https://doi.org/10.1037/0022-0663.81.3.329.

Zimmerman, B.J., 1998. Academic studing and the development of personal skill: A self-regulatory perspective. Educational Psychologist, 33(2-3): 73-86.Available at: https://doi.org/10.1207/s 15326985ep3302\&3_3.

Zimmerman, B.J., 2002. Becoming a self-regulated learner: An overview. Theory Into Practice, 4(2): 64-70.

Zimmerman, B.J. and J. Ringle, 1981. Effects of model persistence and statements of confidence on children's self-efficacy and problem solving. Journal of Educational Psychology, 73(4): 485-481.Available at: https://doi.org/10.1037/0022-0663.73.4.485. 